Case Report

\title{
First local Case Report of a Holocord Pilocytic Astrocytoma - An Uncommon Entity with Management Challenges
}

\author{
Ayesha Arshad, Sheheryar Hanif, Irfan Yusuf, Kamran Hussain \\ Department of Surgical Oncology, Shaukat Khanum Memorial Cancer Hospital and Research Centre
}

\begin{abstract}
Holocord tumors are defined as "Intramedullary spinal tumor extending through the spinal cord with extension from cervicomedullary junction to the conus." They are uncommon tumors having variable presentation and histology. ${ }^{1,2}$ Pilocytic astrocytoma (PA) is a slow-growing tumor, mostly benign. It is the diagnosis in $5 \%$ to $6 \%$ of all intracranial gliomas. ${ }^{3}$ It is the most common tumor in childhood occurring rarely in the adult population. ${ }^{4}$ To date, 25 cases of holocord astrocytoma have been reported, of these, 4 were adults and 21 were children. The management of this unusual disease is challenging and debatable. ${ }^{1,5}$ In this case report, we are describing a case of 14 years old male with holocord grade 1 pilocytic astrocytoma along with its clinical management. To the best of the author's knowledge, this is the first case of a holocord astrocytoma reported in the country.
\end{abstract}

Keywords: Holocord Astrocytoma, Spinal, Intramedullary Tumors, Pilocytic.

Corresponding Author: Dr. Ayesha Arshad

Department of Surgical Oncology, Shaukat Khanum

Memorial Cancer Hospital and Research Centre

Lahore - Pakistan

Date of Submission: 04-07-2021

Date of Revision: 16-08-2021

Date of Acceptance: 31-08-2021

Date of Online Publishing: 30-09-2021

Date of Print: 30-09-2021

DOI: $10.36552 /$ pjns.v25i3.585

INTRODUCTION

PA is a grade I tumor according to World Health Organization (WHO)classification, hence it has a good prognosis. ${ }^{3}$ Until now, 25 cases of holocord astrocytoma have been reported in the literature, 21 of them at childhood ages. There is a slight male predominance. The management of this unusual disease is challenging and debatable. ${ }^{1,5}$ In this case report, we are describing a case of a 14 years old male with holocord grade 1 pilocytic astrocytoma along with its clinical management. To the best of the author's knowledge, this is the first case of a holocord astrocytoma reported in the country.

\section{CASE REPORT}

\section{History and Examination}

A 14 years old male presented with complaints of backache for two months along with ataxic gait and a history of urinary retention off and on for one month. He also had bilateral lower limbs weakness for one month more marked on the right lower limb. On examination, he had paraparesis with a power of 4/5 from L1 down 
with exaggerated reflexes and upgoing plantars. He had somewhat decreased perianal sensations, but the anal tone was intact. A Magnetic Resonance Imaging (MRI) ofthe thoracic spine with contrast was performed on 06/02/2021 at an outside hospital, which showed a heterogeneously enhancing centrally necrotic peripherally enhancing cystic solid mass. The lesion wasintramedullary and causing expansion and thinning of the peripheral margins of the cord. The main component was located posterior to T6 to T7 vertebral bodies. Overall the solid enhancing component of the lesion measured approximately $5 \mathrm{~cm}$ craniocaudally and $2 \mathrm{~cm}$ anteroposteriorly and around $2 \mathrm{~cm}$ transversely. A large cystic component was noted superiorly extending beyond the thoracic spine, as well as inferiorly, a lower limit could not be seen. He was referred to Shaukat Khanum Memorial Cancer Hospital \& Research Centre (SKMCH \& RC) for further management.

MRI whole spine with contrast was done at SKMCH \& RC on 08/03/2021 which showed a large spinal intramedullary tumor with a small enhancing component from T5-T6 level,large multiloculated tumor cysts were noted occupying the rest of the spinal cord. There was spinal cord edema extending till the cervicomedullary junction. The scoliotic deformity was also noted with an apex at T5/6 (Figures 1, a, b \& c). Features favored astrocytoma. MRI brain with contrast was done, which was unremarkable.

The case was discussed in our Neurooncology and spine Multi-Disciplinary-Team meeting, and a decision was made to offer spine surgery for the intramedullary tumor, for biopsy $+/-$ near-total excision of the tumor and decompression of cysts followed by adjuvant chemotherapy and radiotherapy. A Computed tomography-guided wire localization of the right T6 lamina was performed preoperatively for intraoperative localization on 24/05/2021 under local anesthesia.

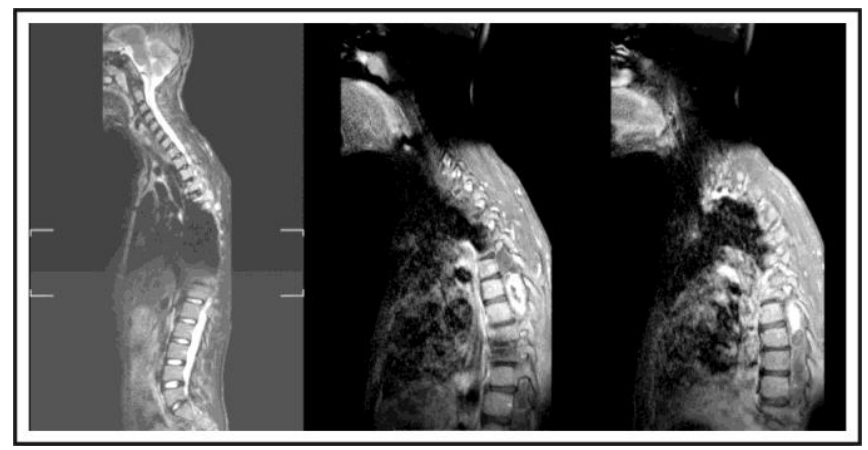

Figure 1a: MRI whole spine T2 weighted image showing the extent of tumor involvement, from $\mathrm{C} 1$ to the conus, the midthoracic cord not visible in this section because of scoliosis. b \& c: MRI thoracic spine with contrast showing the contrast-enhancing part of the tumor opposite $T 5 / 6 / 7$.

\section{Intraoperative}

The patient underwent Fluoroscopic guided decompressive laminectomy of T5, T6 \& T7 vertebrae andsubtotal resection of the intramedullary solid lesion, and decompression of cysts on 25/05/2021.

\section{Intraoperative Findings}

Levo-scoliosis of the thoracic spine, with an apex at T5/6. T5/6/7 level intramedullary solid tumor with multiple cysts above and below the lesion seen. Midline distorted owing to scoliosis and possibly the expansile tumor, with median vein could not be identified. Largely diffuse tumor margins, well-defined at only some places. The tumor was soft but non-suckable. Micro-surgery was employed, cysts decompressed above and below the lesion, lesion excised as much as safely possible, till the margins became diffuse. The frozen section was sent intra-operatively, which came back as a low-grade glial tumor (Astrocytoma).

We aimed to perform resection of the enhancing component of the tumor, mainly behind T5/6/7 vertebral bodies. Initially, the plane was distinct, and we were able to define the tumor, however,the tumor was non-suckable, and 
the margins became diffuse after we had removed almost half of the tumor, Neurophysiological monitoring was not available, hence we did a maximum safe resection only.

\section{Histopathology}

Histopathologyshowed a low-grade glial tumor comprising piloid cells arranged in sheets. Rosenthal fibers and eosinophilic granular bodies are appreciated. IMMUNO/HISTOCHEMICAL STAIN(S): Olig2: Positive, Ki67: 1\% proliferation index. WHO grade I Low grade glioma consistent with Pilocytic astrocytoma (Figure 2).

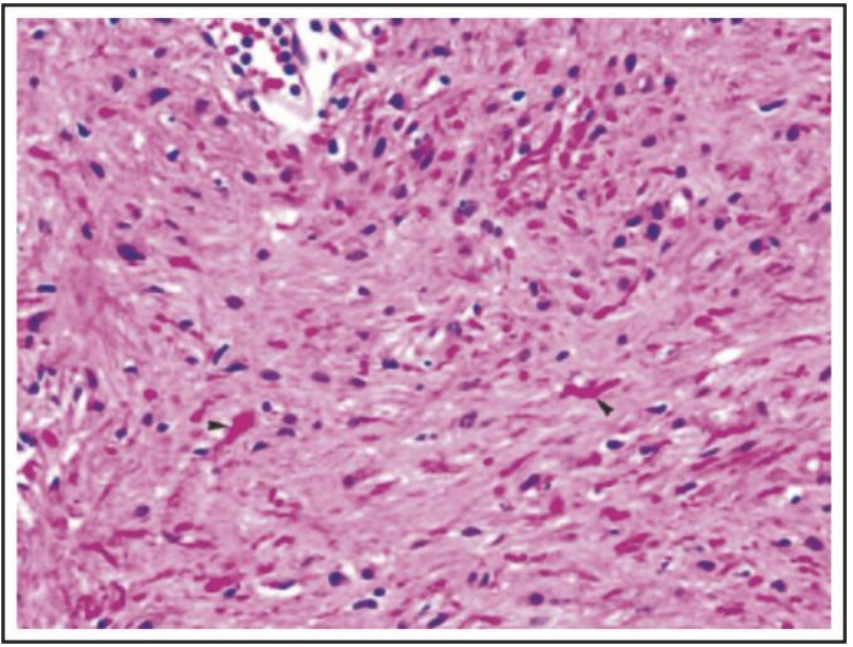

Figure 2: Histopathology sections showed low-grade glial tumor comprising piloid cells arranged in sheets. Rosenthal fibers and the eosinophilic granular bodies, consistent with a diagnosis of a Pilocytic Astrocytoma grade I.

\section{Postoperative Course}

Immediately postoperatively the patient was moving both legs with improved strength subjectively as compared to preoperatively. Sphincter control was intact.

He was kept in bed for three days and then mobilized. He was able to walk with improved power in legs as compared to preoperatively and there was the resolution of urinary retention and back pain.

The postoperative MRI showed a significant reduction in the size of the lesion (Figure3), and he was given chemotherapy on an outpatient basis for residual tumor control.

Three months postoperatively, he is still able to walk without support.

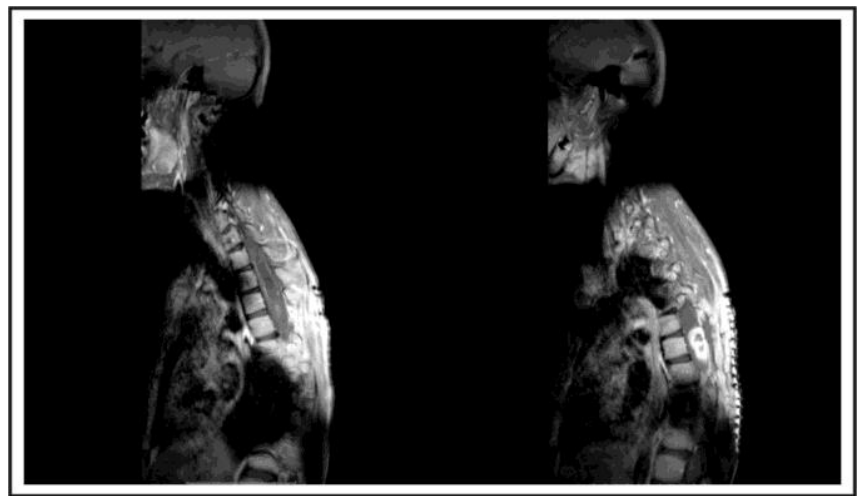

Figure 3: $M R I$ thoracic spine with contrast showing the contrast-enhancing part of the tumor opposite T5/6, now reduced in size after subtotal resection.

\section{DISCUSSION}

Pilocytic astrocytoma is found predominantly in the first two decades of life, although it maybe found in any age group. ${ }^{6,7}$ The 10-year survival rate is $>90 \%$ with treatment-surgery and radiation therapy. ${ }^{8}$ The prevalence is $12.4 \%$ among theprimary spinal tumors in children and adolescentsand $0.8 \%$ in the adult population. ${ }^{9}$

Intramedullary PA of the spinal cord constitutes $70 \%$ of all intramedullary spinal tumors in children. Depending upon location, they can cause significant neurological deficits ${ }^{10}$. There is usually awell-defined margin between normal spinal cord parenchyma. Therefore, in spinal PA, a gross total resection is possible for $50-81 \%$ of the tumor. ${ }^{11}$ We performed a subtotal resection in our case.

An accurate preoperative diagnosis may be helpful in surgical planning and predicting the prognosis. The preferred method of imaging in 
spine tumors is MRI. ${ }^{6}$ MRI provides in detail imaging of soft tissues and spinal cord tumors. Hence it might be possible to classify the tumor as intra- or extradural or intra- or extramedullary. ${ }^{12} \mathrm{MRI}$ findings in Pilocytic Astrocytomas include hypointense lesion on T1weighted conventional sequences and hyperintense on T2-weighted conventional sequences.

Our case is a holocord Pilocytic Astrocytoma. Intramedullary glial neoplasms that affect the entire spinal cord from the cervicomedullary junction to the conus medullaris are called holocord tumors. At least half of the holocord tumors have cysts indistinguishable from solid tumors on T2 weighted studies due to high protein content but show no enhancement with contrast. ${ }^{13,14,15}$

In our case, the patient presented with an outside hospital MRI thoracic spine that showed an intramedullary lesion in the thoracic spine with cysts above and below the lesion, but the extent of the cysts was not visible, hence we did a whole spine MRI with contrast to see the full extent of the cysts and to rule out any other lesions in the spine. That MRI showed us the full nature and extent of the holocord tumor we were dealing with.

This highlights the need for proper preoperative imaging in spine tumors to get a full idea of the lesion especially if one cannot see upper and lower limits.

Because of the paucity of literature on the subject, the management guidelines are still under debate. ${ }^{19,10}$ As per the author's knowledge, we are reporting the first case of holocord pilocytic astrocytoma in the country, we did a subtotal resection of the enhancing component of the tumor and then referred the patient for chemotherapy.

There might be a role of Temozolomide- based chemotherapy in very young children to delay radiation. ${ }^{16}$ As per previous literature, whole spine radiotherapy at the doses of $45 \mathrm{cGy}$ along with chemotherapy is safe and effective.

The patient was given Carboplatin based chemotherapy and whole spine radiotherapy was reserved for recurrence/progression. On the last follow-up in the clinic, the patient is functionally well, walking without the support and the last MRI whole spine with contrast does not show any progression.

\section{CONCLUSION \& RECOMMENDATIONS}

This is the first local case report of an uncommon entity, but there are a few lessons we learned along the way. One of them is that we should always consider this in the differentials if one cannot see the full extent of the intramedullary tumor or its cyst in the MRI sections available. The patient presented with an outside hospital MRI thoracic spine that showed an intramedullary lesion in the thoracic spine with cysts above and below the lesion, but the extent of the cysts was not visible. When we did a whole spine MRI with contrast to see the full extent of the cysts and to rule out any other lesions in the spine, it showed us the full nature and extent of the holocord tumor we were dealing with. This highlights the need for proper pre-operative imaging in spine tumors to get a full idea of the lesion especially if one cannot see the upper and lower limits of the cyst associated with the tumor. Also, in pilocytic astrocytomas of the central nervous system, the standard treatment is to surgically remove the enhancing nodule. Applying the same to spinal holocord astrocytic astrocytomas, we should aim to resect the enhancing part of the tumor. Although we did not have neuromonitoring available, we feel that having intra-operative neuromonitoring would be beneficial in surgery for these tumors, and maximum resection would be possible. 


\section{REFERENCES}

1. Goyal S, Puri T, Julka PK. Holocord low-grade Astrocytoma - Role of radical irradiation and chemotherapy. J Egypt Natl Canc Inst. 2015 Jun; 27 (2): 105-8.

2. Baran O, Kasimcan O, Sav A, Oruckaptan H. Holocord pilocytic astrocytoma in an adult: a rare case report and review of the literature. World Neurosurgery, 2019 Jun. 1; 126: 369-75.

3. Knight J, De Jesus O. Pilocytic Astrocytoma. [Updated 2021 Jul 15]. In: StatPearls [Internet]. Treasure Island (FL): Stat Pearls Publishing, 2021 Jan. Available from: https://www.ncbi.nlm.nih.gov/books/NBK560614/

4. Persson O, Fletcher-Sandersjöö A, Burström G, Edström $E$ and Elmi-Terander $A$. Surgical Treatment of Intra- and Juxtamedullary Spinal Cord Tumors: A Population Based Observational Cohort Study. Front. Neurol. 2019; 10: 814.

5. Ostrom QT, Cioffi G, Gittleman H, Patil N, Waite K, Kruchko C, Barnholtz-Sloan JS. CBTRUS Statistical Report: Primary Brain and Other Central Nervous System Tumors Diagnosed in the United States in 2012-2016. Neuro Oncol. 2019 Nov. 1; 21 (Suppl. 5): v1-v100.

6. She D, Lu Y, Xiong J, Geng D, Yin B. MR imaging features of spinal pilocytic astrocytoma. BMC Med Imaging, 2019; 19: 5.

7. Bond $K M$, Hughes JD, Porter $A L$, Orina J, Fang $S$, Parney I. Adult pilocytic astrocytoma: an institutional series and systematic literature review for extent of resection and recurrence. World Neurosurg. 2018; 110: 276-283.

8. Louis DN, Perry A, Wesseling P, Brat DJ, Cree IA, Figarella-Branger D, Hawkins C, Ng HK, Pfister SM, Reifenberger $G$, Soffietti R, von Deimling A, Ellison DW. The 2021 WHO Classification of Tumors of the Central Nervous System: a summary. Neuro Oncol. 2021; 23 (8): 1231-1251.
9. Ebner FH, Schittenhelm J, Roser F, Scheel- Walter $\mathrm{H}$, Tatagiba M, Schuhmann MU. Management of holocord pilocytic astrocytomas in children and adolescents: an update. Pediatr Neurosurg. 2012; 48: $133-140$.

10. Schittenhelm J, Ebner $F H$, Tatagiba $M$, et al. Holocord pilocytic astrocytoma-case report and review of the literature. Clin Neurol Neurosurg. 2009; 111: 203-207.

11. Almubarak AO, Ulhaq A, BinDahmash A, Al Shail E. Spinal Pilomyxoid Astrocytoma. Pediatr Neurosurg. 2019; 54 (6): 399-404.

12. Samartzis D, Gillis CC, Shih P, O'Toole JE, Fessler RG. Intramedullary spinal cord tumors: part Iepidemiology, pathophysiology, and diagnosis. Glob Spine J. 2015; 5: 425-435.

13. Kutluk $T$, Varan $A$, Kafalı $C$, Hayran $M$, Söylemezoğlu F, Zorlu F, Aydın B, Yalçın B, Akyüz $C$, Büyükpamukçu $M$. Pediatric intramedullary spinal cord tumors: a single center experience. Eur J Paediatr Neurol. 2015 Jan; 19 (1): 41-7.

14. Zhang, Y. W., Chai, R. C., Cao, R., Jiang, W. J., Liu, W. H., Xu, Y. L., Yang, J., Wang, Y. Z., \& Jia, W. Q. (2020). Clinicopathological characteristics and survival of spinal cord astrocytomas. Cancer Medicine, 9 (19): 6996-7006.

15. Chou SC, Kuo MF, Lai DM, Chen CM, Xiao F, Tsuang FY, Yang SH. Contemporary management of pediatric spinal tumors: a single institute's experience in Taiwan in the modern era. J Neurooncol. 2020 Feb; 146 (3): 501-511.

16. Ahmed R, Menezes AH, Torner JC. Role of resection and adjuvant therapy in long-term disease outcomes for low-grade pediatric intramedullary spinal cord tumors. J Neurosurg Pediatr. 2016 Nov; 18 (5): 594-601. 


\section{Additional Information}

Disclosures: Authors report no conflict of interest.

Ethical review statements: For the case report, approval was taken from the hospital Ethical Review Committee.

Human Subjects: Consent was obtained by the patient in this study.

Conflicts of Interest:

In compliance with the ICMJE uniform disclosure form, all authors declare the following:

Financial Relationships: All authors have declared that they have no financial relationships at present or within the previous three years with any organizations that might have an interest in the submitted work.

Other Relationships: All authors have declared that there are no other relationships or activities that could appear to have influenced the submitted work.

\section{AUTHORS CONTRIBUTIONS}

\begin{tabular}{|l|l|l|}
\hline Sr.\# & Author's Full Name & Intellectual Contribution to Paper in Terms of: \\
\hline 1. & Ayesha Arshad & Study design and methodology \\
\hline 2. & Sheheryar Hanif & Paper writing and data calculations \\
\hline 3. & Irfan Yousaf & Data collection and calculations \\
\hline 4. & Kamran Hussain & Analysis of data and interpretation of results etc. \\
\hline 5. & Ayesha Arshad & Literature review and referencing \\
\hline 6. & Ayesha Arshad & Analysis of data and quality insurer \\
\hline
\end{tabular}

